\section{Os Estudos de etnometodologia de Garfinkel: uma investigação sobre os alicerces morais da vida pública moderna*}

Recebido: 18.04 .18

Aprovado: 01.06.18
Anne Warfield Rawls**

Resumo: A Editora Vozes publicou uma tradução em português da nova segunda edição de Estudos de etnometodologia. Para comemorar essa realização, falarei hoje a respeito da importância desse livro, da obra de Garfinkel em geral, em termos teóricos, metodológicos e políticos. Argumentarei que Garfinkel se dedicou ao projeto durkheimiano de fazer com que a sociologia se tornasse singularmente adequada para o estudo da modernidade, e que isso explica muitas das incompreensões sofridas por esta obra. Quero também anunciar as atividades do Arquivo Garfinkel (Garfinkel Archive), do qual sou hoje diretora e executora intelectual. Há materiais no arquivo que deverão se tornar o foco de importantes teses de pós-graduação e livros. O trabalho com esses arquivos vem sendo apoiado pelo governo alemão por meio de um centro na Universidade de Siegen, na Alemanha, denominado Mídia da Cooperação.

O argumento de Garfinkel, assim como o de Durkheim, modifica o território epistemológico da ciência social e, com ele, o território teórico da argumentação social. Ele reorienta o domínio dos objetos, fazendo com que eles deixem de ser objetos naturais para se tornarem objetos sociais; vem como o domínio das práticas sociais relevantes, que deixam de ser normas, regras tradicionais e consensos, para se tornarem práticas constitutivas. Em razão da magnitude dessa reorientação, a etnometodologia só pode ser entendida por pessoas que já tenham uma compreensão teórica do que ela envolve. De outra forma, surgiriam contradições, o que de fato já aconteceu. A consequência do argumento de Garfinkel para entender a política democrática moderna é que quaisquer desigualdades ou exclusões que impeçam as pessoas de estar em condições de cumprir as condições de reciprocidade de uma interação (suas famosas "condições de confiabilidade") são uma ameaça à coerência, ao significado e à identidade da vida pública democrática moderna.

Palavras-chave: Teoria sociológica contemporânea. Estudos de etnometodologia. Garfinkel. Fatos sociais constitutivos. Justiça social como questão sociológica.

\section{Garfinkel's studies in ethnomethodology: exploring the moral foundations of modern public life}

Abstract: Editora Vozes has published a Portuguese translation of the new second edition of Studies in ethnomethodology. To celebrate that achievement I will talk about the importance of that book and of Garfinkel's work more generally; in theoretical, methodological and political terms. I will argue that Garfinkel took up Durkheim's project to make Sociology uniquely suited to the study of modernity and that this explains much of the misunderstanding of his work. I also want to announce the existence of Garfinkel's Archive of which I am the Director and Intellectual Executor. There are materials in the Archive that should become the focus of important graduate theses and books. Work on the archive is being supported by the German government through a center at Siegen University in Germany called Media of Cooperation.

\author{
* Tradução: \\ Dermeval de Sena \\ Aires Júnior. \\ ** Anne Warfield \\ Rawls é professora \\ de sociologia, \\ Universidade de \\ Bentley, Waltham, \\ Massachusetts, \\ Estados Unidos; \\ professora de \\ socioinformática, \\ Universidade de \\ Siegen, Renânia \\ do Norte-Vestfália; \\ Alemanha; diretora \\ do Garfinkel Archive; \\ Universidade de \\ Bentley, Waltham \\ (MA), Estados \\ Unidos da América. \\ <arawls@bentley. \\ edu>.
}


Garfinkel's argument - like Durkheim's - changes the epistemological terrain of social science, and hence the theoretical terrain of social argumentation. It shifts the domain of objects from natural to social objects - and the relevant social practices from norms, traditional rules and consensus - to constitutive practices. Because of the enormity of this shift, Ethnomethodology can only be understood by those with a theoretical grasp of what is involved. Otherwise, contradictions follow: as they have. The consequence of Garfinkel's argument for understanding modern democratic politics is that any inequalities or exclusions that prevent people from being able to fulfill reciprocity conditions in interaction (his famous "Trust Conditions") are a threat to coherence, meaning, and identity in modern democratic public life.

Keywords: Contemporary sociological theory. Studies of etnomethodology. Garfinkel. Constitutive social facts. Social justice as a sociological question.

\section{Introdução}

A

obra Estudos em etnometodologia se tornou um clássico logo após sua publicação, em 1967. Seu argumento desafiou as premissas da teoria e da pesquisa social convencionais, gerando tanto um grande entusiasmo como profundas controvérsias. Os estudos propostos por Garfinkel demandavam mudanças na concepção de ciência social e da sociedade durante a turbulenta década de 1960, no sentido de que o momento e a mensagem se encaixavam bem. Porém, se, por um lado, isso aumentava o interesse naquela época, por outro, também encorajava a ideia de que o seu argumento estava circunscrito à década de 1960, e tanto Garfinkel quanto a etnometodologia passaram a ser associados à contracultura e, desde então, a tendências anti-intelectuais.

O trabalho de reposicionar Garfinkel historicamente nos ajuda a esclarecer o seu posicionamento, que tomou forma nas décadas de 1930 e 1940, isto é, mais de 20 anos antes da publicação dos Estudos. Garfinkel obteve o seu Master of Arts na primavera de 1942 e passou alguns anos, durante a Segunda Guerra Mundial, fazendo pesquisas para o Exército. Também é relevante o fato de que ele pertencia a uma minoria judia que, entre 1939 e 1946, viveu em uma parte racialmente segregada da América do Norte, onde chegou pessoalmente a ter sua entrada impedida em hotéis e restaurantes reservados apenas para "brancos". Tais experiências serviram como insumo para a produção intelectual de sua juventude sobre a dinâmica interacionista da desigualdade racial. Seu intercâmbio com Howard Odum (cuja especialidade era a cultura negra folk) encorajou-o a adotar esse enfoque e o levou a desenvolver os seus argumentos de que as condições de confiabilidade são um pilar necessário para a interação humana, e de que as desigualdades que levam à perda das condições de confiabilidade ameaçam a possibilidade de uma vida pública democrática moderna. 
A abordagem de Garfinkel pertence a uma importante linha de pesquisa social desenvolvida na década de 1930 e profundamente enraizada no desafio lançado por Durkheim ao individualismo de Comte. Segundo essa linha, em alguns contextos, os fatos sociais apenas existem quando e à medida que sejam criados de modo cooperativo. De acordo com a defesa feita por Talcott Parsons, essa linha de raciocínio começou a desafiar o primado do indivíduo e os objetos epistêmicos endêmicos à teoria e à filosofia social então estabelecidas.

Nos anos 1930, Parsons (1933) começou a apresentar Durkheim e Weber a pensadores sociais norte-americanos, argumentando que o que aparentava ser um conjunto de contradições muito complicadas em termos de teoria e método eram, na verdade, apenas artefatos resultantes da preservação do individualismo e do positivismo de Comte e Spencer. Pelo argumento de Parsons (1938), a cisão quantitativa/qualitativa na sociologia resultava inteiramente dessa deficiência teórica. Uma solução simples, portanto, estaria ao alcance: abraçar as novas ideias, socialmente mais centradas, de Durkheim e Weber. Parsons (1949) também argumentou a favor da abordagem da cultura como esfera independente de ação social. Ao trabalhar com Parsons, Garfinkel adicionou importantes subsídios a esse novo posicionamento "europeu". Ao enfatizar o caráter irredutivelmente cooperativo e ordenado das ações sociais significativas, Garfinkel contribuiu com a transformadora ideia de que os participantes das situações sociais compartilham métodos (etnométodos/métodos dos membros) que são constitutivos em relação ao significado e aos objetos sociais que eles produzem conjuntamente. Em 1962, chamou a isto "a descoberta da cultura" (Garfinkel, 1961-1962).

Esse raciocínio - de que os objetos sociais são criados a cada ocasião situada, por pessoas que cooperam a fim de cumprir critérios constitutivos, e de que elas continuam em mudança a cada novo movimento - modifica o terreno epistemológico, pois coloca os fatos sociais e as condições empíricas (ou métodos empíricos) por elas engendradas no centro da investigação social. Como esses métodos precisam ser coordenados entre os participantes de uma interação a cada momento, as propriedades constitutivas devem ser presenciáveis e ensináveis; e todos os participantes devem ser minimamente livres e iguais para utilizá-las sem constrangimento. Consequentemente, os etnométodos compartilhados são moralmente relevantes e testemunháveis empiricamente.

Interpretar esse enfoque empírico como enfoque positivista é um erro. Os fatos naturais e os objetos epistêmicos do positivismo foram, aqui, rejeitados. Os critérios presenciáveis considerados para a geração de fatos sociais são fundamentalmente 
sociais e cooperativos, e a capacidade que os participantes têm de reconhecê-los torna-os empiricamente disponíveis. O observador estuda como os participantes orientam e criam a sua "realidade" compartilhada. As implicações tanto para a teoria quanto para o método são transformadoras: os "conceitos" e as clarificações a seu respeito deixam de estar no centro da teoria e do método. Questões tradicionais relacionadas ao positivismo, subjetivismo/objetivismo, realismo/idealismo, e assim por diante, revelam-se como artefatos da abordagem clássica - como afirmaram Parsons e Durkheim.

Onde a nova abordagem dos fatos sociais constitutivos foi entendida, ela conseguiu inspirar trabalhos nas fronteiras da ciência social: em estudos de ciência e matemática, gênero, raça, criminalidade, comportamentos divergentes, policiamento, teoria organizacional, comunicação, pragmatismo interativo, interações entre médicos e pacientes, informação e desenho técnico, etnografia institucional, estudos no local de trabalho, interações homem/computador e estudos culturais (Rawls, 2008a).

Infelizmente, a tendência de analisar essa abordagem, a partir dos próprios arcabouços que ela desafia, gerou muita contradição. Assim, apesar de seu impacto, as implicações do posicionamento de Garfinkel em relação à teoria e à pesquisa foram incompreendidas. Tratar a etnometodologia como área de especialidade dentro de um contexto teórico que ainda pressupõe o caráter natural do indivíduo e dos objetos epistêmicos - pressuposições estas que a linhagem dos fatos sociais constitutivos, de Durkheim a Garfinkel, rejeitou - é um contrassenso.

Durkheim argumentou que uma mudança epistemológica em direção às práticas constitutivas transformaria questões de lógica e razão em questões sociológicas; e que, ao substituir o individualismo e o naturalismo no centro das coisas, essa mudança colocaria a sociologia no centro tanto da filosofia quanto das ciências sociais. Do mesmo modo, Garfinkel insistiu que a adoção de um rigoroso posicionamento constitutivo - que trata todos os objetos sociais significativos como produtos colaborativos - reorientaria os parâmetros teóricos de tal forma que a teoria social anterior e seu método se tornariam irrelevantes. Garfinkel se referiu a isso como a "indiferença" da etnometodologia ao integrar questões sociológicas e filosóficas. Wittgenstein também argumentou nesse mesmo sentido.

A indiferença não diz respeito a questões de igualdade e justiça - que permanecem no centro da investigação etnometodológica - e sim a pressupostos presentes na maneira como as questões foram colocadas. O argumento de Garfinkel sobre a confiabilidade, assim como as "condições tácitas de contrato", de Durkheim, também 
trata da reciprocidade e da igualdade necessária para mantê-la, como elementos essenciais para o sentido e a coerência da ação social. Isso se torna ainda mais importante à medida que a sociedade se diversifica. Por sua vez, a indiferença tem a ver com questões relacionadas a indivíduos, ao ponto de vista de um ator, aos objetos epistêmicos/naturais, e aos valores e consensos de grupo, que são artefatos diretos do positivismo e do individualismo.

A mudança epistemológica pela qual os indivíduos e objetos sociais passam a ser tratados como produtos cooperativos é, para Durkheim, o fator que distingue a sociologia de outras disciplinas. Nesse sentido, o caráter cooperativo dos fatos sociais é a chave para superar o positivismo (e os vieses culturais que permeavam os seus pressupostos); e, por sua vez, as ordens constitutivas e cooperativas são a chave para moldar uma teoria adequada da ordem e da igualdade democrática em uma sociedade moderna diversificada, onde o consenso já não mais existe. Apesar de a sociologia, em termos gerais, ter falhado em adotar a perspectiva de Durkheim, alterando-a de formas estranhas a fim de ajustá-la aos pressupostos teóricos então adotados, o projeto de Garfinkel é profundamente sociológico, no sentido original de Durkheim. Porém, como a mudança epistemológica realizada tanto por Durkheim quanto por Garfinkel foi mal compreendida, o potencial de seus insights para informar a teoria social, política e econômica contemporânea permaneceu não aproveitado. A teoria e a pesquisa seguem hoje comprometidas, atreladas ao positivismo e sobrecarregadas de contradições.

É verdade que houve diversos motivos pelos quais essas implicações teóricas foram mal compreendidas. Porém, o período da guerra teve um peso desproporcional como fator capaz de minar a linhagem do fato social. A tendência de situar Garfinkel na década de 1960 - ao invés de situá-lo na de 1940 - teve não apenas o efeito de menosprezar as mudanças que aconteceram na sociologia durante a Segunda Guerra - que, por sua vez, tiveram efeitos sobre todos os sociólogos qualitativos, incluindo o próprio Garfinkel (Rawls, 2018) -, mas teve ainda o resultado de apartar o seu trabalho do esforço de Parsons para reviver Durkheim e embasar uma nova abordagem sociológica para a cultura nas práticas sociais. Situar Garfinkel na década de 1940, isto é, no momento em que ele estava formulando suas ideias, contribui um pouco para reparar esse erro, mostrando-o como defensor da linhagem do fato social constitutivo em face de seus críticos do período da guerra - e não como um crítico da hegemonia disciplinar então vigente, tal como foi erroneamente descrito mais tarde. Como estudante de universidades de elite que se colocou ombro a ombro com os seus influentes orientadores, Garfinkel participou de um debate disciplinar de alto nível em um momento histórico crucial. Esse era o contexto em que ele formulou sua argumentação. 
Apesar de outras influências que atuaram no desenvolvimento da sociologia no pós-guerra - como o medo do comunismo na década de 1950 -, a reorganização que ocorreu durante o período da guerra explica muito. Em contraste com as duas décadas anteriores, com seus amplos debates e discussões, a guerra levou a um rápido afunilamento do enfoque disciplinar e a um aumento da emotividade em relação à ciência. Os sociólogos também queriam aportar com sua contribuição, e fazê-lo com rapidez. Queriam o apoio do governo, e queriam receber o respeito dispensado a outros pesquisadores e cientistas. Ao buscarem avidamente "unificar" uma concepção de "sociologia científica" com a produção de resultados rápidos em auxílio ao esforço de guerra, insistiram em suprimir abordagens qualitativas e interacionais para questões sociológicas (Rawls, 2018).

Essa abordagem de sociologia foi sempre capaz de gerar novas questões e reenquadrar as existentes de novas maneiras. Mas a sociologia de Garfinkel não era uma sociologia "californiana" do movimento da contracultura dos anos 1960, ao contrário do que afirmou Lewis Coser (1975), ao presidir a American Sociological Association (ASA), em 1975. Na década de 1940, Garfinkel esteve ao lado de expoentes consagrados da disciplina nas universidades de Harvard, Princeton e Chapel-Hill em defesa da linhagem do fato social, enfrentando as investidas que os líderes da sociologia fizeram contra ele na época da guerra.

O lado de Garfinkel ainda não venceu esse debate. Entretanto, um exame das circunstâncias do período de guerra, quando a disputa foi decidida, sugere que o processo foi apressurado, enviesado, chauvinista e voltado ao esforço de guerra, ao invés de se fundamentar em uma consideração cuidadosa dos argumentos. Como resultado, a sociologia foi lançada para fora de seu caminho, perdendo o seu objeto peculiar - os fatos sociais - e sendo suplantada pelo pragmatismo, o pós-modernismo, a psicologia e a economia.

Tudo isso foi desnecessário. A abordagem do fato social é mais sofisticada do que isso. A perspectiva de Garfinkel tem o potencial de restaurar o projeto sociológico original de Durkheim. Assim, há muito tempo que uma reavaliação sobre o tema deveria ter sido feita.

\section{Para situar o desenvolvimento das ideias de Garfinkel na década de 1940}

Garfinkel pertence à geração que amadureceu antes da Segunda Guerra Mundial. Nascido em 1917, ingressou na faculdade em 1935 e concluiu seu Master of Arts em maio de 1942, versando sobre o "Homicídio intra e inter racial". Após sua gradua- 
ção, alistou-se no Exército e serviu como pesquisador no centro de Gulfport Field, Mississippi, de dezembro de 1942 a janeiro de 1946. Apesar de ser apenas cinco anos mais velho do que Goffman, sua experiência acadêmica anterior à guerra e seu trabalho como sociólogo profissional, já em plena guerra, marcam o início de sua prática. Garfinkel estava, então, com 35 anos de idade e já havia escrito mais de uma dúzia de manuscritos significativos antes de concluir seu doutoramento em junho de 1952, junto a Parsons, em Harvard, com a tese intitulada "A percepção do outro: um estudo da ordem social". Garfinkel tinha 50 anos de idade quando os Estudos foram publicados.

O pensamento de Garfinkel entre 1939 e 1952 foi pelo menos tão influenciado por gigantes como Howard Odum (1943), Florian Znaniecki (1936), W. I. Thomas, Talcott Parsons(1933, 1938, 1949), Robert Bales e Wilbert Moore - juntamente com acadêmicos de destaque em outras disciplinas, como Kenneth Burke, Jerome Bruner (1990), Herbert Simon, Paul Lazarsfeld e Gregory Bateson -, quanto pela fenomenologia de Edmund Husserl, Alfred Schutz e Aaron Gurwitsch, à qual costuma ser mais associado.

Descrito posteriormente como rebelde, Garfinkel trabalhou junto a importantes elites de sua disciplina na Carolina do Norte (Howard Odum, Guy Johnson); em Harvard (Talcott Parsons, Robert Bales, Jerome Bruner, Charles Mosteller); e em Princeton (Wilbert Moore, Melvin Tumin, Gregory Batesone, Herbert Simon). Garfinkel continuou trabalhando com importantes figuras após sua chegada na University of California, Los Angeles (Ucla) (Robert Boguslaw, Warren Pelton, Erving Goffman, Egon Bittner, Harvey Sacks, Emmanuel Schegloff, Aron Cicourel, David Sudnow, Mike Lynche, Lindsay Churchill), e, entre 1959 e 1968, esteve em Harvard com Parsons, Elliott Mishler, Steve Lorch e Mike McGuire, do Massachusetts Institute of Technology (MIT), auxiliares de Joseph Weizenbaum no projeto computacional Eliza.

\section{A transição do período da guerra}

O fato de Garfinkel estar inicialmente situado no centro da sociologia - e apenas mais adiante ter avançado para as suas margens, após a disciplina ter se modificado - é relevante. Durante a guerra, a sociologia passou por uma grande transformação. O estreitamento da disciplina, iniciado nesse período, continuou e gerou impactos na recepção das ideias de Garfinkel (como também ocorreu com toda a linhagem do fato social constitutivo e com as abordagens interacionistas, em termos amplos). Tal estreitamento também teve impactos sobre os esforços feitos por Parsons para reintroduzir Durkheim. Pode-se argumentar que a amplamente anunciada "crise" da 
sociologia no final dos anos 1960 deveu-se à transformação vivenciada no período da guerra e à sua supressão da linhagem dos fatos sociais.

Enquanto a história canônica da disciplina conta uma história de mudanças incrementais como resultado dos avanços científicos (Hinkel, 1994; Bannister, 1987; Turner, 2005), existe também - felizmente - o registro de uma narrativa oposta, denominada por Howard Odum (1943) como o "frenesi" do período da guerra e da reação dos líderes da disciplina de então. A ASA e seus líderes eleitos deixaram um registro de suas preocupações no período da guerra por meio dos discursos proferidos por seus presidentes nas reuniões anuais da entidade, que estão publicados na American Sociological Review (ASR). Essas palestras são um inestimável registro narrativo das questões políticas, científicas e ideológicas que impulsionaram a transformação da disciplina durante a guerra. Esse testemunho desafia a visão canônica de uma lenta mudança científica, desvelando, ao contrário, um apressado frenesi entre os líderes da disciplina, que queriam fazer a sua parte para ajudar a salvar o mundo e garantir que a sociologia não ficaria de fora, enquanto o governo dos Estados Unidos financiava a pesquisa de guerra de outras disciplinas. Em sua narrativa, esse registro mostra que a sociologia como disciplina passou rapidamente a ser observada nos termos ditados pelas particularidades do pensamento do período da guerra.

Como narrativas, esses discursos permitem-nos sentir algo do contexto acadêmico no qual Garfinkel viveu e trabalhou quando estava na Carolina do Norte e em Harvard. Passados tantos anos, eles são hoje, de fato, um recurso de valor incalculável. Nos anos em que foi orientador da tese de Garfinkel, Parsons ocupou influentes funções em comitês da ASA e, em 1947, atuou como representante da ASA no Congresso dos Estados Unidos para tratar da recém-proposta National Science Foundation (NSF). Parsons tornou-se presidente da ASA em 1949. Por sua vez, Howard Odum foi presidente da ASA em 1930 e continuou como figura muito influente. E Florian Znaniecki, autor de Social actions (1936), por quem Garfinkel afirmou ter sido influenciado, atuou em diferentes comitês, juntamente com Parsons, nos anos 1940 e foi eleito presidente da ASA em 1954.

Garfinkel teve um lugar na primeira fileira nos debates dessa época. Seus escritos iniciais podem ser vistos como um esforço de responder aos desafios enfrentados pela sociologia durante os anos da guerra, e esteve ao lado de Parsons e outros líderes da disciplina, defendendo-se contra uma visão ingênua e positivista da sociologia como uma ciência "unificada", que estava sendo adotada em resposta à guerra. 
No contexto da Segunda Guerra Mundial - e diante da crença de que o destino do mundo pendia na balança -, a ASA começou a se reestruturar prontamente em 1939. Seus membros achavam que não tinham sido suficientemente combativos durante a Primeira Guerra Mundial e expressaram o sentimento de que o seu fracasso em agir anteriormente constituía sua parcela de responsabilidade diante do malogro da paz. Eles não estavam dispostos a repetir o mesmo erro. Na Europa ocupada, a pesquisa social foi ou interrompida ou cooptada pelo Estado e assim os Estados Unidos se tornaram, efetivamente, o centro da pesquisa científica social.

Além de criar comitês para tratar das demandas da guerra, a ASA lançou um chamado de unidade científica, apoiando-se amplamente da crença de Comte, de que a unidade é necessária para o progresso científico. No caso, "unidade" significava estar de acordo com uma única forma de fazer sociologia - uma forma que não seria qualitativa. A visão comtiana de um consenso aterrissou na sociologia norte-americana, no final do século XIX, por intermédio de Albion Small e Louis Wirth, em Chicago. $\mathrm{O}$ argumento de Durkheim, mais sofisticado, de que a ciência e a sociedade modernas requerem uma diversidade de perspectivas (a visão da prática constitutiva), foi defendido por Parsons e pelo grupo de Harvard no período da guerra, mas foi pesadamente criticado pelos líderes da ASA, que permaneceram fiéis a Comte.

\section{A busca por uma unificação da ciência}

Engajados em um profundo autoexame e preocupados com a possibilidade de que a sociologia não estivesse sendo suficientemente científica a ponto de realizar uma contribuição efetiva ao esforço de guerra, os líderes da disciplina traçaram um caminho ao longo dos sete anos de duração do conflito, dando seguimento à interpretação comtiana da "ciência" como abordagem estreitamente definida e "unificada". Naquela época, a sociologia não era respeitada. Os líderes eleitos atribuíram tal falta de reconhecimento ao enfoque dado pela disciplina aos problemas sociais e à justiça social, além da falta de união e do rigor da teoria e do método (representado, a seu ver, pelo campo da estatística). Esses líderes externaram a crença de que a sociologia foi rotulada como empreendimento esquerdista de "assistência social" e não estava sendo levada a sério como ciência, uma vez que os interesses de justiça social não seriam científicos. Como ao final da Segunda Guerra Mundial, a Rússia deixou de ser aliada para tornar-se inimiga dos Estados Unidos, o argumento "avesso a valores" tornou-se cada vez mais insistente.

Durkheim, contrariando essa lucubração, argumenta que a questão da justiça é a questão científica que está no próprio âmago da sociologia moderna. Acadêmico 
com forte interesse pela justiça social, e acreditando que a justiça e a ordem social não podem estar separadas, Garfinkel se propôs a provar este ponto (Rawls, 2017). Infelizmente, a estreita visão unificadora prevaleceu e a ideia de que as questões qualitativas da justiça e da ordem são científicas foi rejeitada. Em prol da unidade, os líderes da disciplina sociológica começaram a redefini-la de forma a excluir as abordagens etnográficas, qualitativas e interacionais. Isso implicou em reduzir os detalhes empíricos à seara dos "conceitos claros" e em subordinar os "dados" resultantes à austeridade das fórmulas estatísticas. A ênfase colocada tanto por Durkheim quanto por Weber nos detalhes, no contexto e na competência situacional, e por Durkheim, em particular, no caráter constitutivo dos fatos sociais, foi rejeitada. Os líderes da disciplina expressaram uma veemente urgência a esse respeito. Externaram até mesmo a preocupação de que a sociedade democrática moderna sucumbiria se não lograsse identificar com rapidez os requisitos "científicos" da sociedade democrática e não a apoiasse efetivamente.

Durkheim estaria de acordo com a preocupação acerca da sociedade democrática e por isso defenderia com fervor um foco nos requisitos morais. Desafortunadamente, os líderes do período da guerra acreditavam que a "ciência" (isto é, a manipulação de dados estatísticos) precisava ser apartada dos "valores" então atribuídos à democracia. Não atentavam para a realidade de que entender o que a democracia é, e entender o que é necessário para engendrá-la e mantê-la, deve preceder à busca pelos requisitos científicos, e que esse exame praticamente não pode evitar "valores".

\section{Do centro para a margem}

À medida que a transformação disciplinar acontecia, Garfinkel encontrou suas próprias preocupações, que iniciaram no centro da disciplina e avançaram continuamente em direção às margens. A mudança rumo ao formalismo, com sua tendência a ocultar questões de importância central para a sociologia em nome da ciência, tornou-se um foco de interesse para Garfinkel. Começou a tratar de problemas relacionados aos novos métodos (aos quais denominou de "análise formal"), à crescente dependência em relação a pressupostos da linguagem e à eficácia de conceitos, por assim dizer, "bem definidos". Sua produção durante a década de 1940 sondou o deslocamento da disciplina no momento mesmo em que ocorria. Mais adiante, seu trabalho passou a tratar das curiosas contradições que esse deslocamento gerou na sociologia.

Essas mudanças de orientação disciplinar não apenas enfatizaram uma unificação teórica e metodológica, mas pintavam a dissidência em tons antipatrióticos no con- 
texto de guerra: dissidentes eram vistos como traidores. Isso explica grande parte das incompreensões relacionadas à forma como Garfinkel passou a ser considerado. Mesmo tendo fundamentado os seus argumentos a partir de Parsons e articulado uma teoria da ação social totalmente focada na ação social, Garfinkel foi tratado como se estivesse atacando a sociologia.

Na verdade, Garfinkel estava abrindo questões teóricas essenciais em um momento em que os líderes da disciplina estavam empenhados em fechá-las. Defendia a sociologia como ciência, enquanto os líderes da disciplina efetuavam mudanças anticientíficas, com suas proibições em relação a perspectivas divergentes. A guerra teve sobre a ciência o mesmo efeito que tinha em seu apelo geral de "erguer a bandeira". De repente, apenas uma abordagem se tornou aceitável - a única bandeira que podia ser erguida -, e todos deveriam abraçá-la.

Com a publicação da Estrutura das revoluções científicas de Thomas Kuhn, em 1962, os paradigmas passaram a ser reconhecidos como maneira eficaz de se fazer ciência. A partir de então, a filosofia da ciência argumentou que a especialização, tanto quanto a discordância, é necessária para a ciência - assim como Durkheim já afirmara em 1893. Porém, a essa altura, a sociologia norte-americana já havia adotado a visão de que sua unidade e neutralidade valorativa eram necessárias. 0 pensamento interdisciplinar e as novas ideias - a exemplo das que Garfinkel estava formulando - foram distorcidos a fim de que pudessem ser encaixados nessa visão. Ironicamente, os sociólogos conseguiram incorporar os insights de Kuhn para justificar o crescente de paradigmas gerados a partir do esforço de unificação, sem, no entanto, abrir mão de qualquer uma das mudanças realizadas no período da guerra em decorrência de sua crença em tal unificação.

Garfinkel não estava só ao temer que o melhor da sociologia estivesse se perdendo. Outros acadêmicos profundamente comprometidos com o pragmatismo, a interatividade, a etnografia, as abordagens linguísticas naturais e a ideia de que os fatos sociais são ordens constitutivas trabalharam arduamente para defender seus posicionamentos. A Society for the Study of Social Problems (SSSP) e, mais adiante, a Society for the Study of Symbolic Interaction (SSSI) romperam com o status quo e constituíram suas próprias associações, em 1951 e 1973, respectivamente. Os assistentes sociais já haviam rompido décadas antes, em 1918, e os sociólogos rurais, em 1937. Muitos acadêmicos tinham visões diferentes daquelas defendidas pelos líderes eleitos de suas associações e estavam profundamente preocupados. 


\section{Garfinkel em Harvard: o ápice da controvérsia}

Nos seis anos em que estudou com Parsons em Harvard (1946-1952), Garfinkel vivenciou o ápice dessa controvérsia. Enquanto Parsons continuou argumentando pela importância da "nova" teoria europeia que defendia, Homans, também em Harvard, opunha-se a ele e manifestava-se a favor de uma abordagem individualista reducionista. Garfinkel se viu no meio da discussão, enquanto os sociólogos de Harvard literalmente racharam, resultado da forte pressão exercida por essas diferenças. Parsons foi fundamental para a criação do novo e interdisciplinar Departamento de Relações Sociais, em 1946, fruto de seu empenho na condição de diretor permanente e seu mentor, com vistas a preservar o caráter eclético da teoria e da pesquisa social.

A posição de Parsons, como representante da ASA, junto à nova Fundação Nacional da Ciência, em 1946, foi decisiva. Enquanto exercia essa função, Parsons recebeu a solicitação de preparar um relatório a respeito do papel das ciências sociais no desenvolvimento geral da ciência. Entre outros pontos, argumentou que cada ruptura tecnológica traria, em sua esteira, uma mudança social. Portanto, se a ciência natural estava sendo financiada pelo governo, era também imperativo que a ciência social recebesse recursos para estudar as mudanças sociais que se seguiriam. E se a sociologia era uma ciência imatura, tal como alegavam alguns dos seus críticos, Parsons argumentou que era ainda mais importante impulsioná-la com recursos públicos, para que ela pudesse se sofisticar a ponto de conseguir explicar as mudanças sociais resultantes das rápidas mudanças tecnológicas que estavam ocorrendo.

Em 1949, Parsons tornou-se presidente da ASA e, durante a década seguinte, esteve no centro da disciplina sociológica, atuando também como secretário da ASA por muitos anos, a partir do início dos anos 1960. Seu destaque deve ter permitido a Garfinkel familiarizar-se em primeira mão, e em tempo real, com os debates entre os líderes da disciplina, assegurando-lhe, por exemplo, a discussão do discurso do presidente Carl Taylor, que propunha uma "sociologia do bom senso" (em inglês, "sociology of common sense"), em aulas que Garfinkel frequentou em 1946. A abordagem de Garfinkel para a sociologia ampara-se inteiramente no common sense - na contribuição de um entendimento do common sense para a ciência -, e na maneira como a ciência se realiza por meio de práticas reais de bom senso cooperativo. 


\section{Narrativa do tempo de guerra versus história disciplinar}

Em contraste com os relatos canônicos de como a sociologia lenta e metodicamente se desenvolveu como ciência, com a "Escola de Columbia" supostamente vencendo a "Escola de Chicago" (ver Rawls, 2018, para uma revisão dessa literatura), impressiona na leitura dos discursos dos presidentes da ASA entre 1940 e 1947 o quão rapidamente ocorreu a transformação do período da guerra, o quão emotiva ela foi e o quão premente pareceu ser para aqueles que estavam discursando. O primeiro chamado à ação foi feito pelo presidente da ASA Robert Maclver, da Universidade de Columbia, que abriu o seu discurso de dezembro de 1940 aos membros da associação - "Algumas reflexões sobre a sociologia durante uma crise" - com palavras inflamadas:

\footnotetext{
Quando uma tempestade balança uma casa, nós nos preocupamos com as suas fundações. Quando uma crise desafia as nossas rotinas, somos forçados a repensar os valores sobre os quais elas se assentam [...] precisamos fazer uma reavaliação. Isso vale para os nossos valores intelectuais, não menos do que para o restante das coisas. Nossa vocação acadêmica, nossa aprendizagem, nossa pesquisa: como elas se apresentam no contexto de um tempo em que pequenos e grandes Estados soçobram, e em que os mares e céus estão preenchidos com a morte... (Maclver, 1941: 1).
}

Garfinkel foi um dos que atenderam ao chamado à ação, alistando-se no Exército assim que concluiu sua dissertação de Master of Arts na primavera de 1942. Enquanto as tropas de Hitler assolavam a Europa, Garfinkel - um intelectual judeu profundamente preocupado com a justiça social - trabalhou duro para valer-se de suas habilidades como sociólogo em auxílio ao seu país. Sua relação de longo prazo com a Força Aérea, que pareceu estranha em meio ao clima antiguerra dos anos 1960, iniciou-se com o seu patriotismo no período da guerra. Ao engajar-se em pesquisas para a Força Aérea, em Gulfport Field, entre 1942 e 1946, Garfinkel estava também reavaliando as maneiras pelas quais a sua ciência poderia alçar-se para lidar com a crise.

Como primeiro dos presidentes da ASA durante a guerra, Robert Maclver expressou, em 1940, uma visão ampla e eclética do aprimoramento da sociologia como ciência. Apesar de argumentar que a sociologia carecia de uma rápida mudança, Maclver defendia o estudo das diferenças culturais (à semelhança de um projeto de pesquisa sobre atitudes norte-americanas em relação à Rússia, no qual Garfinkel chegou a trabalhar em Harvard, em 1947). Maclver também propôs fortalecer o que 
há de diferente na sociologia, e seus métodos eram ecléticos. Ele fortaleceria o que a sociologia faz que outras disciplinas não conseguem fazer, argumentando que "é praxe das outras ciências evitar" os ídolos socialmente criados da tribo, o mercado e o teatro, enquanto que "é praxe das ciências sociais estudá-los". Maclver foi o primeiro dos líderes do período da guerra que enfocou a própria guerra e a mudança iminente. Mas as modificações que defendeu não tratavam de excluir quaisquer teorias ou métodos; apenas tópicos.

Entretanto, ano a ano os presidentes da ASA se tornaram mais e mais estreitos em suas propostas acerca do enfoque e dos métodos que deveriam adotar para fortalecer a sua ciência, e a sua visão relativa à transformação da disciplina rapidamente começou a afunilar-se. Em seus discursos, os presidentes da ASA em 1941 (Stuart Queen) e 1942 (Dwight Sanderson) continuaram empregando uma retórica de chamamentos amplos à ação. Porém, suas propostas de como os resultados deveriam ser alcançados tornaram-se cada vez mais específicas. Além disso, diferentemente de Maclver, os presidentes que o sucederam quiseram fortalecer as características capazes de tornar a sociologia mais semelhante às outras ciências, ao invés de fortalecer o que ela tinha de diferente. Tal tendência continuou mesmo após o término da guerra.

As propostas dos discursos de 1943 a 1945 (George Lundberg, Rupert Vance e Kimball Young) tornaram-se tão específicas que o surgimento de graves discordâncias foi inevitável. Lundberg adotou a visão mais extrema, defendendo a demografia como o melhor modelo para a ciência, e advertindo contra as "panaceias dos magos" (referindo-se às perspectivas qualitativas e a qualquer interesse em questões de justiça). Para Lundberg, o interesse de um sociólogo em justiça seria "como se os engenheiros se tornassem primariamente interessados na justiça de um deslizamento de terra". Lundberg também teceu acerbas críticas religiosas e raciais à influência judaica na teoria social. Garfinkel, ao contrário, argumentou consistentemente - como já o fizera Durkheim - que como a realização dos fatos sociais - e a capacidade de comunicar-se - requer a cooperação, os processos que dão embasamento à geração de um fato social têm um caráter intrinsecamente moral. Ignorar essa qualidade moral em favor de uma ilusão de "objetividade" implica a irônica consequência de permitir a penetração de vieses morais nos próprios objetos dos dados - uma característica que Garfinkel (1946) apontou como "etnocentrismo". 


\section{A nova teoria social europeia: redefinindo os fatos sociais}

No centro dessa controvérsia, sem ser reconhecido, estava o fato de que a distinção da sociologia como disciplina constituía grande parte do problema. Comte e Spencer distinguiram a sociologia de outras disciplinas apontando para a existência dos fatos sociais (referindo-se a símbolos, valores e instituições sociais) como fenômenos especiais passíveis de estudo pela sociologia. Porém, ao delinearem a sociologia como uma nova abordagem, mantiveram o primado do indivíduo e dos objetos epistêmicos; e os fatos sociais que colocaram no centro da nova disciplina eram, em ampla medida, resíduos do agregado de ações individuais ao longo do tempo. Tal individualismo inerente preservou uma semelhança básica entre a sociologia e outras disciplinas, a despeito da ênfase que a sociologia colocou no fato social, implicando que a pesquisa requer generalizações (tanto demográficas quanto ao longo do tempo e do espaço), e excluindo o significado científico do estudo de qualquer interação específica.

Durkheim deu um passo ainda mais radical, reconhecendo o status criado e imediato de certos fatos sociais, e definindo-os em termos de práticas e expectativas reconhecíveis. Isso prontamente tornou relevantes instâncias específicas da prática, como Durkheim (1912) argumentou nas Formas elementares (Rawls, 1996a; 2008a). Muitas críticas e incompreensões relativas a Durkheim são explicadas pelo fato de que ele elaborou esse argumento contra o individualismo em um contexto cultural no qual o individualismo era altamente valorizado (ver Rawls, 1996b).

O argumento inicial de Durkheim em sua introdução de 1893 à Divisão do trabalho social posicionou os "fatos sociais" em oposição ao ponto de partida individualista e natural dos fatos, que os economistas, psicólogos e filósofos tendiam a tomar como algo que está dado. Durkheim concordava com Comte quanto à premissa geral de que os fatos sociais são o objeto especial da sociologia, mas discordava dele em relação ao que são os fatos sociais, e como surgem. Comte enfatizara o papel dos valores sociais na formação do comportamento individual, já Durkheim adotou uma visão mais radical, segundo a qual o próprio indivíduo é um produto social e, portanto, é também um fato social.

Durkheim argumentou que os fatos sociais criados pela ação prática em cooperação, e não por motivos individuais para realizar valores, constituem o objeto específico de estudo da sociologia. Nas Formas elementares, documentou com grande cuidado os processos de geração de tais fatos sociais, apresentando o argumento 
epistemologicamente revolucionário de que a origem das categorias básicas da razão pode ser explicada dessa maneira (ver Rawls, 1996a; 1996b). Em seu livro O suicídio, ocupou-se da psicologia. Durkheim argumentou que outras ciências tomam como algo dado, como se fossem fatos naturais, as características do indivíduo, as situações e os mercados econômicos, os quais apenas existem como resultado de relações e práticas sociais específicas. Estes são fatos sociais, não fatos naturais.

A ideia de que os fatos sociais são um tipo especial de fato e demandam, portanto, uma abordagem social especial em sua observação e análise, não apenas colocou os sociólogos em dissonância com as demais disciplinas, mas também os colocou em dissonância com grande parte das crenças do senso comum da cultura ocidental. Apesar de a sociologia norte-americana ter sempre mantido subjacente uma corrente de individualismo, antes da Segunda Guerra Mundial existia uma concordância geral acerca da importância dos fatos sociais, pelo menos da forma entendida por Comte. Isso, por um lado, ocasionava críticas a partir de outras disciplinas, mas também distinguia a sociologia como uma ciência da modernidade.

Porém, na década de 1940, ocorreu uma drástica guinada em direção à psicologia, à economia e uma orientação para os fatos naturais individualistas por parte dos líderes da disciplina. Essa foi uma guinada contra o que distingue a sociologia como disciplina. Mas ela estava alinhada ao seu tempo. No final dos anos 1920, Parsons (1938) atribuiu o início dessa guinada à inadequação da tradição teórica de Comte e Spencer. A inovação de Durkheim não sofreu da mesma incapacidade de explicar a modernidade, tampouco do mesmo distanciamento em relação à pesquisa. Mas a defesa que Parsons fez do novo posicionamento europeu aconteceu fora de um tempo adequado, e ainda se tornou objeto de influentes interpretações equivocadas (Merton, 1934). O mito do indivíduo - e do individualismo - estava ganhando força na vida norte-americana durante e após a guerra. Os esforços para situar o consenso que a maioria dos sociólogos (que seguiam a Comte, ao invés de Durkheim) acreditavam ser necessário na sociedade do pós-guerra levaram, na ausência de um consenso mais significativo, a um enfoque na "sociedade de massa" e na "comunicação de massa".

Nesse ambiente, um enfoque em práticas situadas foi considerado algo banal - a guerra, em sua essência, exprimiu a perda do centro moral da sociedade. Entretanto, pela visão de Durkheim a respeito das práticas constitutivas, a justiça e a igualdade devem aumentar - ao invés de diminuir - à medida que as sociedades se tornem mais diferenciadas, uma vez que a cooperação necessária para sustentar as práticas situadas requer a igualdade. 
Com embasamento predominantemente em Comte - ao invés de Durkheim -, a prática acadêmica neutralizou esse argumento e levou a uma visão oposta: a modernidade estaria corroendo a moralidade. O argumento de David Reisman (1950) em A multidão solitária (1950) - justamente acerca de um novo individualismo, que estaria a erodir a vida grupal, a evidenciar que a personalidade moderna havia se tornado amoral e instrumental - é típico dessa visão. Existia então - e ainda existe uma tendência a associar a ação prática ou instrumental à falta de moralidade. A associação da moralidade a modos tradicionais de vida, com suas profundas histórias, está por trás de tais preocupações. A ideia de Durkheim e de Garfinkel - de que há um contrato social espontâneo no âmago das ações sociais cooperativas coerentes, de modo que até mesmo a mais instrumental das ações se baseia na reciprocidade e na cooperação - não estava na tela do radar.

Isso contribuiu para uma desconsideração dos requisitos morais da sociedade moderna tanto pela ciência quanto pelo governo. Além dessas incompreensões teóricas, os números e as tecnologias numéricas foram envolvidos por uma poderosa aura mística. Ambas as tendências de pensamento - o individualismo e os números - fortaleceram uma abordagem sociológica de fatos naturais durante e após a guerra, e estão estrangulando a sociologia na atualidade. Em 1960, Homans (figura central para a derrocada de Parsons em Harvard), declarou, como presidente da ASA, que não existem fenômenos distintivamente sociológicos: não existem fatos sociais. A sociologia, desse modo, seria apenas outra forma de psicologia.

\section{O lugar de Garfinkel nesta linhagem}

A visão cada vez mais pessimista do caráter moral e racional da pessoa moderna, e a atitude a ela relacionada - de pessimismo em relação à sociedade -, que se apresentaram na época, foram combatidas por Garfinkel (assim como também o foram por Durkheim e Parsons).

Garfinkel não pensava que as pessoas modernas haviam se tornado inerentemente imorais, ou que o individualismo estava erodindo a vida grupal. Sustentou que os sociólogos estariam chegando a tais conclusões por tratarem o ator como um "dopado cultural". Em oposição, situou o contrato social no centro das interações. Seu famoso argumento da "confiabilidade" - cujas sementes podem ser vistas em diversos manuscritos seus de 1946-1947 - é uma tentativa de documentar isso.

O problema era simples. Os sociólogos da orientação predominante estavam procurando questões morais no lugar errado: em formas sociais tradicionais baseadas no consenso, às quais Garfinkel se referiu em sua juventude como o consenso "tribal". 
Como eles estavam se pautando em um consenso obsoleto proveniente de modos de vida tradicionais, eram incapazes de enxergar o contrato social no compromisso moral cooperativo dos atos sociais que, juntos, engendravam o universo de fatos sociais que aconteciam por toda parte ao seu redor.

O argumento de Garfinkel a respeito da razão situada, seus requisitos e efeitos, em seus manuscritos de 1952-1953 relativos à informação, tem muito em comum com a visão otimista de sociedade contemporânea encontrada em Durkheim, que identifica a liberdade e a democracia tanto como resultados quanto como condições subjacentes às relações sociais constitutivas modernas.

Assim como Durkheim, Garfinkel não tratou a liberdade como o resultado de se libertar da sociedade. Ao invés disso, considerou-a como o resultado da cooperação concentrada em práticas constitutivas que estão livres da tradição (consenso tribal). Em sociedades diferenciadas, uma unidade forçada e hegemônica simplesmente não pode ser mantida. Em seu lugar, desenvolvem-se as práticas constitutivas que requerem a cooperação mútua e a reciprocidade. O que faz a sociedade moderna funcionar é o fato de que a ordem e a coerência, no lugar de um consenso baseado em modos de vida tradicionais, dependem do compromisso mútuo com as práticas constitutivas. Esse processo requer uma grande medida de reciprocidade e igualdade. Isto, por sua vez, produz a liberdade individual. E ainda torna a liberdade científica possível. O embasamento dos fatos sociais em práticas de cooperação liberta o pensamento e permite que a ciência dê um passo à frente da crença - tal como Durkheim argumentou em suas conferências a respeito do pragmatismo.

Ao invés de tornar a sociologia mais semelhante às outras ciências sociais e naturais - a abordagem então favorecida pelos líderes da disciplina -, Garfinkel favoreceu uma abordagem capaz de manter a distinção entre a sociologia e demais disciplinas, enfatizando os processos que geram os fatos sociais. Porém, para opor-se à intensa tendência ao reducionismo na sociologia, seria também necessário demonstrar, de uma vez por todas, que existem fatos sociais que não são fatos naturais, e que, portanto, não podem ser estudados fora dos seus contextos sociais; isto, a fim de mostrar que a disciplina possui, de fato, objetos de dados distintos, que devem ser estudados qualitativamente.

Pela perspectiva de Garfinkel, essa tarefa requereria desconstruir alguns pressupostos que estavam obstruindo o caminho. Os pressupostos de que a linguagem simplesmente funciona, e de que magicamente estamos todos a enxergar os mesmos objetos sociais, eram duas suposições que Garfinkel teve bem firme em seu 
campo de visão. O pressuposto de que a pesquisa social deveria avançar com base no ponto de vista do ator era outra dessas suposições. Garfinkel tomou a peito o desafio de remover esses obstáculos e, a partir de 1946, desenvolveu o que denominou de "teoria dos objetos sociais", como base para uma sociologia contemporânea da ação, comunicação e interação (Garfinkel, 1946). Comprometeu-se, assim, a colocar a interação (a essência do que acontece entre as pessoas) na teoria da ação: quando as pessoas fazem um sentido conjunto, fazem-no valendo-se de regras (práticas) constitutivas, às quais Garfinkel chamou de "etnométodos". Para que a democracia funcione, a cooperação baseada na prática e essencialmente igualitária precisa substituir a forma "tribal" de consenso, que estabelece fronteiras entre as pessoas.

\section{Conclusão}

Enquanto as elites predominantes da disciplina, em seu esforço de torná-la mais científica, estavam na verdade abandonando a própria ideia e os fatos sociais que definem a sociologia, Garfinkel lutou para resgatar esta ideia fundamental, enfatizando o caráter constitutivo dos objetos sociais, e exortou Parsons a fazer o mesmo. A contínua colaboração dos dois autores, durante toda a década de 1960, sugere que ambos se dedicaram a essa tarefa com seriedade e apreciaram mutuamente os seus esforços. Mas a despeito do seu compromisso com esse projeto e de sua importância, e ainda que a filosofia da ciência nos anos 1950 tenha rejeitado a visão comtiana de unidade (no sentido de consenso) em favor das "comunidades de prática", interpolando-as com insights revolucionários (em diferentes fases), a orientação predominante na sociologia continuou apegada à unidade.

As questões teóricas que Garfinkel apontou na década de 1940 - a respeito do status constitutivo dos objetos sociais - já haviam sido a chave da argumentação de Durkheim (em 1893 e, novamente, em 1912), e estavam na própria base de sua ideia de sociologia como disciplina. Essas questões foram levantadas novamente em 1958 por Winch em sua obra A ideia de uma ciência social, porém, como se fossem ideias novas.

Garfinkel transformou, explorou e expandiu um importante domínio da investigação sociológica, antes defendido insistentemente por Durkheim, que envolve as maneiras como as coerências mútuas são criadas e sustentadas entre as pessoas. Essa abordagem é particularmente adequada para o estudo da cooperação social em espaços públicos modernos, dando assim continuidade à ênfase colocada por Durkheim na crescente importância das práticas constitutivas e na justiça nas sociedades modernas. 
Porém, apesar da grande importância dessas questões relacionadas ao status constitutivo dos fatos sociais, elas foram tratadas durante décadas por líderes centrais da disciplina como algo banal e incompatível com a ciência. Ao considerar a dedicação dos líderes da disciplina acerca da abordagem científica, saltam aos olhos o caráter frequentemente emotivo, ideológico e não científico de sua reação a Garfinkel, e sua omissão quanto a questões centrais da sociologia (além de sua persistente leitura equivocada de Durkheim).

A verdadeira barreira ao progresso científico na sociologia era então - e continua sendo hoje - o fato de que os líderes da disciplina tomam os fatos sociais como algo que está simplesmente dado. Garfinkel, em contraste, seguiu Durkheim e tratou os fatos sociais como os objetos fundamentais que requerem explicações. Garfinkel também tratou a justiça em contextos de cooperação como uma questão científica - seguindo, uma vez mais, a Durkheim. Essa questão de como os fatos sociais são engendrados, e qual é a relação entre a sua geração e a realização da justiça social, tem um significado essencial. Na visão de Durkheim, é precisamente ela o alicerce de todas as ciências modernas - e não apenas a sociologia. É importante, pois, que a sociologia tome posse dessa questão.

\section{Referências}

BANNISTER, R. Sociology and scientism: the american quest for objectivity, 18801940. Chapel Hill (NC): University of North Carolina Press, 1987.

BRUNER, J. Acts of meaning. Cambridge (MA): Harvard University Press, 1990.

COSER L. Two methods in search of substance. American Sociological Review, v. 40, p. 691-700, 1975.

DURKHEIM, E. Suicide. London: Penguin, 1995 [1897].

_. La division sociale du travail. Paris: Alcan, 1984 [1893].

- The elementary forms of the religious life. London: George Allen \& Unwin Ltd., 1912.

GARFINKEL, H. Studies in ethnomethodology. 2. ed. London: Routledge Press. Portuguese translation by Editora Vozes, 2018 [1967].

Seeing sociologically. Boulder (CO): Paradigm Publishers, 2006 [1948]. 
- Essays in ethnomethodology. Unpublished manuscript in the Garfinkel Archive, 1961-1962.

- Notes on the information apperception test. Unpublished manuscript in the Garfinkel Archive, 1947.

Some reflections on action theory and the theory of social systems. Unpublished manuscript in the Garfinkel Archive, 1946.

- Inter and intra racial homicide. MA Thesis. Version published in Social Forces, 1949 [1942].

GOULDNER, A. The coming crisis of western sociology. New York: Basic Books, 1970.

HINKLE, R. Developments in american sociological theory 1915-1950. Albany (NY): State University of New York Press, 1994.

MACIVER. R. Presidential address: "Some reflections on sociology during a crisis". AmericanSociological Review, v. 6, n. 1, p. 1-8, 1941.

MERTON, R. Durkheim's division of labor in society. American Journal of Sociology, 40, n. 3, p. 319-328, Nov. 1934.

ODUM, H. Race and rumors of race: the American South in the early forties. Baltimore (MD): Johns Hopkins University Press, 1943.

PARSONS, T. Presidential address. "The prospects of sociological theory". American Sociological Review, v. 15, n. 1, p. 3-16, 1949.

- The role of theory in social research. American Sociological Review, v. 3, n. 1 p. 13-20, 1938.

. The structure of social action. Chicago (IL):Free Press, 1933.

QUEEN, S. Presidential address. "Can sociologists face reality?" American Sociological Review, v. 7, n. 1, p. 1-12, 1942.

RAWLS, A. The wartime narrative in US sociology: stigmatizing qualitative sociology in the name of science. The European Journal of Sociology, p. 1-21, DOI 10.1177/1368431018754499, 2018.

- An essay on the intrinsic relationship between social facts and moral questions. Canadian Journal of Sociology, v. 54, n. 4, p. 392-404, 2017.

. Harold Garfinkel, ethnomethodology and workplace studies. Organization Studies. Special Symposium Issue. v. 29, n. 5, p. 701-732, 2008a. 
- Epistemology and practice. Cambridge (MA): Cambridge University Press, 2008b [2004].

- Durkheim's epistemology: the neglected argument. American Journal of Sociology, v. 102, n. 2 p. 430-482, 1996 a.

- Durkheim's epistemology: the initial critique 1915-1924. Sociological Quarterly, v. 38, n. 1, p. 111-145, 1996b.

REISMAN, David. The lonely crowd: a study of the changing American character. New Haven (CT): Yale University Press, 1950.

SANDERSON, D. Presidential address. "Sociology: a means to democracy". American Sociological Review, v. 8, n. 1, p. 1-9, 1943.

TAYLOR, C. Presidential address: "Sociology and commonsense". American Sociological Review, v. 12, n. 1, p. 1-9, 1947.

TURNER, S. A life in the first half-century of sociology: Charles Ellwood and the division of sociology. In: CALHOUN, C. (Ed.). Sociology in America: a history, p. 115-154. Chicago (IL): University ChicagoPress, 2005.

VANCE, R. Presidential address. "Toward social dynamics". American Sociological Review, v. 10, n. 2, p. 123-127, 1945.

WEBER, M. The protestant ethic and the spirit of capitalism. New York: Scribner, 1905.

WINCH, P. The idea of a social science. London: Routledge \& Kegan Paul, 1958.

WIRTH, L. Presidential address. "Consensus and mass communication". American Sociological Review, v. 13, n. 1, p. 1-15, 1947.

WITtgensteIN, L. Philosophical investigations. Oxford (UK): Oxford University Press, 1953.

YOUNG, K. Presidential address. "Society and the state: some neglected areas of research and theory". American Sociological Review, v. 11, n. 2, p. 137-146, 1946.

ZNANIECKI, F. Social actions. New York: Farrar \& Rinehart, 1936. 